\title{
Epidemiology of ovarian cancer
}

\section{Patricia Gaona-Luviano, Lourdes Adriana Medina-Gaona, Kassandra Magaña-Pérez}

Department of Surgery, Section of Gynecology, National Institute of Medical Sciences and Nutrition "Salvador Zubirán”, Mexico City, Mexico

Contributions: (I) Conception and design: P Gaona-Luviano; (II) Administrative support: P Gaona-Luviano; (III) Provision of study materials or patients: LA Medina-Gaona, K Magaña-Pérez; (IV) Collection and assembly of data: All authors; (V) Data analysis and interpretation: All authors; (VI) Manuscript writing: All authors; (VII) Final approval of manuscript: All authors.

Correspondence to: Patricia Gaona-Luviano, MD. Department of Surgery, Section of Gynecology, National Institute of Medical Sciences and Nutrition “Salvador Zubirán”, Vasco de Quiroga 15, Colonia Sección XVI, Tlalpan, Mexico City, 14000, Mexico. Email: gaonapatricia@hotmail.com.

\begin{abstract}
Worldwide, ovarian cancer (OC) is the seventh most common type of malignant neoplasm in women and the eighth cause of mortality in them. The classification of OC is made by the possible origin of one of the three main components of the ovary: epithelium, stroma, and germinal cells. Due to this the main malignant tumors arising from the ovary are epithelial carcinoma, germ cell tumor, sex cord-stromal tumor, and Krukenberg's tumor. The most common are the epithelial carcinomas, in which the most prevalent is serous ovarian carcinoma. Nevertheless, the subtype of OC varies according to the age of appearance. The global incidence of OC has been stable during the last decades, but, it's still a disease that has contributed to a considerable number of deaths around the world. The epidemiology of this cancer shows differences between races and countries due to several factors including genetic and economic. The detection of this cancer has been problematic as there is no screening public program for its early detection and as a consequence, most OCs are detected in an advanced stage where most of the time it has already spread to other parts different from the ovary. The purpose of this article is to present a comprehensive review of the general epidemiology, incidence rates, prevalence rates, mortality, and survival of the different types of OC worldwide and in certain regions.
\end{abstract}

Keywords: Ovarian carcinoma (OC); germ cells tumor; Krukenberg's tumor; sex cord stromal tumor; epidemiology; incidence; mortality; survival rates

Submitted Jan 20, 2020. Accepted for publication Jun 17, 2020.

doi: $10.21037 /$ cco-20-34

View this article at: http://dx.doi.org/10.21037/cco-20-34

Ovarian cancer (OC) occupies the seventh place between malignant tumors and the eighth-place as a cause of death from cancer in women in the world (1). In addition, to be one of the most common gynecologic cancers, they have the highest mortality rate between them and occupy the third place in mortality, only after cervical and uterine cancer (1). The frequency of this cancer varies according to countries and ethnicity. In 2012, the highest incidence of OC was registered in the North of Europe and the United States, and the lowest incidence was reported in Japan (Figure 1) (2). According to ethnic groups, the highest prevalence is between Caucasian women (12 per 100,000), followed by Hispanic (10.3 per 100,000), African-American (0.4 per 100,000), and Asian women
(9.2 per 100,000). Nevertheless, the highest mortality of OC is more significant in African populations (1). This high mortality may be related to the social determinants of health. Factors such as poverty and poor access to health may have an impact on the outcome of OC (3) as in other diseases. Nevertheless, it is also important to mention that nowadays there is no screening program in public health in order to detect it on time. Several methods have been reviewed such as CA-125, a transvaginal ultrasound, and bimanual examination, despite the efforts none of them have shown to be effective to be implemented as a public measure (4). Compared to other cancers OC does not occupy an important place in the number of deaths compared to lung, colorectum, or stomach. Nevertheless, 


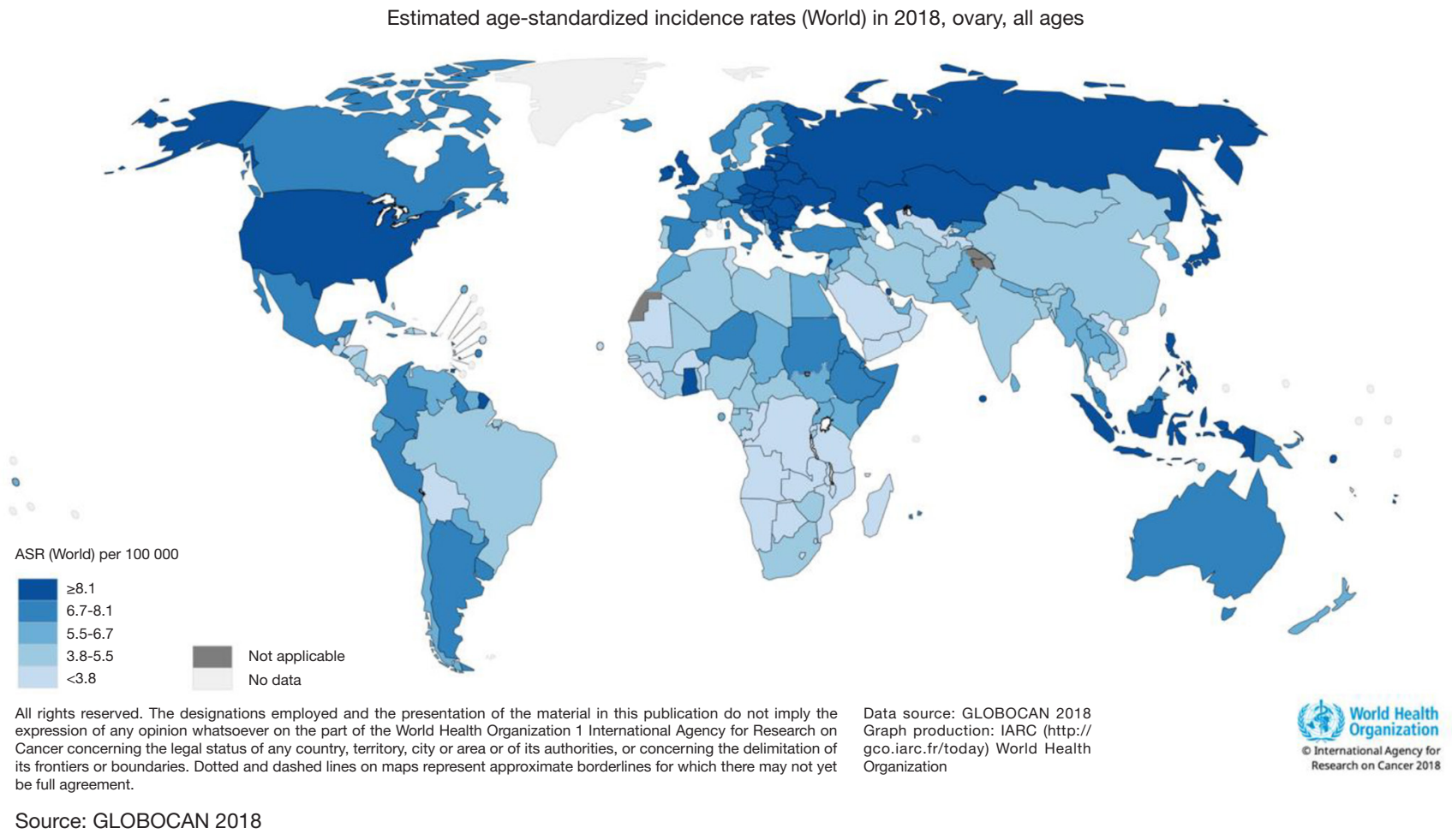

Figure 1 Incidence of ovarian cancer worldwide.

in Globocan 2018 an incidence of 295,414 new cases were reported of OC, with a total of 184,799 deaths. Globally the incidence in 2018 was 6.6 per 100,000 and mortality 3.9 (Figures 1,2). Regarding Mexico, this platform reported an incidence of 6.8 with a mortality of 4.0 , similar to the average worldwide. On the other side in China OC doesn't occupy a place in the top 10 cancers in 2018, being the first one breast cancer, lung cancer, and third place colorectum (5). Despite the low incidence that may be perceived, OC it's a public health problem, as it occupies important mortality and morbidity in women.

OC is classified in different subtypes (Figure 3), being the most common one the epithelial OC (2), only $10 \%$ is has a non-epithelial origin (1). Predominant subtype has five major histologies that differ in their origin, pathogenesis, molecular profile, risk factors for their development, and clinical prognosis (2). Among epithelial OC, 97\% are nonmucinous and 3\% mucinous. Mucinous tumors presented different histotypes like serous (70\%), endometroid (10\%), clear cell $(10 \%)$, and unspecified $(5 \%)$. Of the serous subtype, two other groups have been described: high grade and low grade (1).

The staging of the OC was initially defined by the FIGO in 1988, and it was actualized in 2014. It defines four stages: Stage I are tumors confined to ovaries: IA is a tumor limited to one ovary, with no capsule rupture, with no tumor on the surface and negative washings; and IB is defined as a tumor that involves both ovaries and otherwise is like IA; IC1 is a tumor with a surgical spill in 1 or both ovaries; IC2 is a tumor with preoperative rupture of the capsule or tumor present on the ovarian surface; IC3 is defined as malignant cells in the ascites or peritoneal washings. Stage II is an OC that involves one or both ovaries with pelvic extension or primary peritoneal cancer; IIA is when the tumor has extension and/or implant on the uterus and/ or Fallopian tubes and IIB when there is an extension to other pelvic intraperitoneal tissues. Stage III is a tumor that involves one or both ovaries with cytological or histologically confirmed spread to the peritoneum outside the pelvis and/or metastasis to the retroperitoneal lymph nodes; IIIA is a tumor with positive retroperitoneal lymph nodes and/or microscopic metastasis beyond the pelvis; IIIB represents macroscopic peritoneal metastasis $<2 \mathrm{~cm}$ outside the pelvis and IIIC is defined as peritoneal metastasis $>2 \mathrm{~cm}$ outside the pelvis and/or positive retroperitoneal lymph nodes. Finally, Stage IV includes distant metastasis 
Estimated age-standardized mortality rates (World) in 2018, ovary, all ages

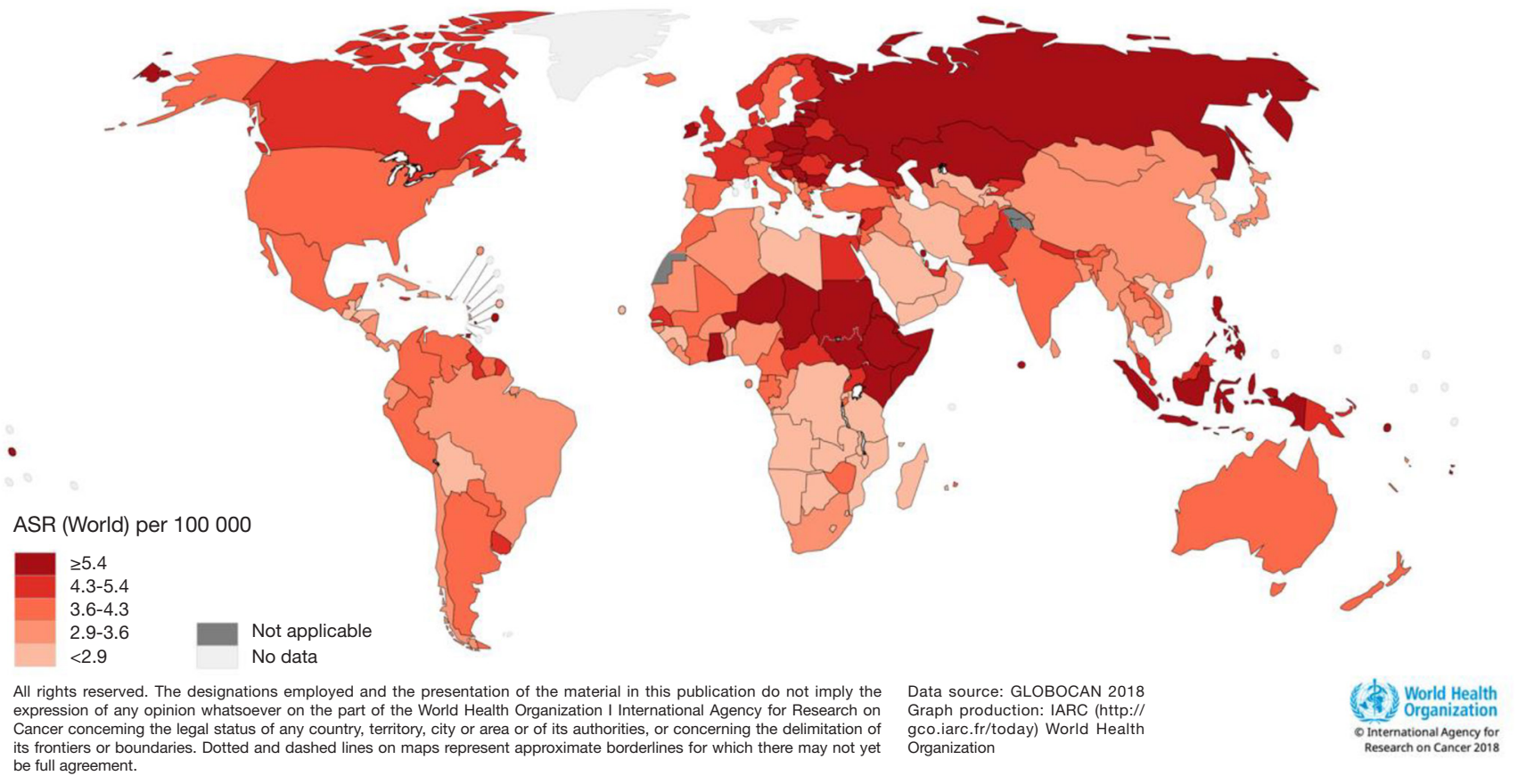

\section{Source: GLOBOCAN 2018}

Figure 2 Mortality of ovarian cancer worldwide.

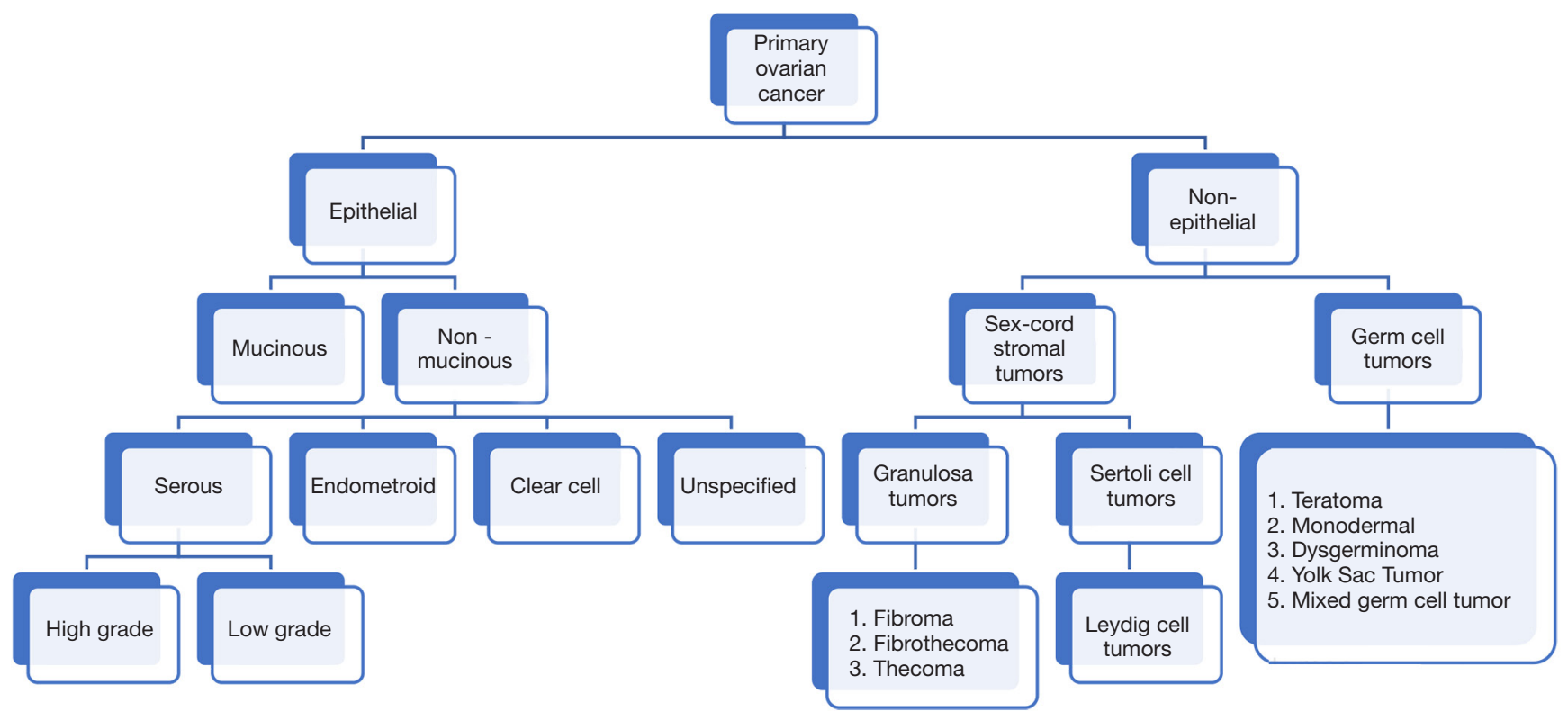

Figure 3 Classification of ovarian cancer. 
out of peritoneal implants; IVA, when there is a malignant pleural effusion confirmed with cytology and IVB is the presence of other types of distant metastasis like parenchymal hepatic or splenic metastasis (6). OC is a histologic diagnosis. The histopathologic evaluation is performed following surgical removal of an ovary, fallopian tube, or biopsies of the peritoneum. Infrequently (approximately 20 percent of women with advanced disease will be managed this way), the diagnosis is performed on analysis of fluid or tissue retrieved by ultrasound or computed tomography-guided biopsy, paracentesis or thoracentesis. The treatment will depend on the histology of OC, tumor stage according to FIGO, and the particular conditions of the patient.

The stage of the OC will vary according to the moment of diagnosis. Serous carcinomas usually are diagnosed in advanced stages, $51 \%$ are stage III and $29 \%$ stage IV, being one of the most aggressive subtypes of OC. On the other hand, the majority are diagnosed in stage I (58\% to $64 \%$ ). Because of the diagnosis and stage, survival to 5 years is $43 \%$ in the serous subtype, in contrast to endometroid (82\%), mucinous (71\%), and clear cell carcinoma (66\%). As mentioned before race/ethnicity also influences the survival rates (7).

Different risk factors have been described related to OC. We can divide these risk factors in demographic, reproductive, gynecologic, hormonal, genetic, and related to lifestyle. Despite the deep searching in this topic some of the variables described are controversial in their correlation with the development of OC (Table 1). Most OC is sporadic, only $5 \%$ to $10 \%$ of them are of familial origin (2). Nevertheless, it is important to mention that one of the stronger risk factors for $\mathrm{OC}$ is a family history of the disease. Mutations in the BCRA1 and BCRA2 genes have also been correlated to the increased risk of OC $(8,9)$.

Age has been described as a predisposing factor for the development of OC. Increasing risk of OC has been observed in patients with a larger number of ovulatory cycles like patients with younger age at menarche and late age of menopause. Increasing the number of ovulatory cycles increases cellular divisions predisposing to the development of malignant neoplasms $(10,11)$. OC is considered mainly postmenopausal disease. It has also been seen in several studies that an older age increases the risk of a more aggressive type of tumor, the median age for the diagnosis is $50-79$ years although these vary according to the region as mentioned before (1).

Other factors such as breastfeeding have shown to be a protective factor for the development of OC. Lactation during 3 months may be enough to reduce the risk. The correlation of protecting factors has also been described in women that took contraceptives and gave birth to children (12-14).

At last, there are factors that have been studied but make controversy in their correlation in the increased risk of developing OC. Nutrition, diet, lifestyle, and physical activity have been recently researched as possible predisposing factors. It has been seen that women with increased levels of fatty acid metabolites increased the risk of OC (15).

Other conditions that seem to be protectors are the bilateral tubal occlusion and the hysterectomy (16). Endometriosis has been reported as a risk factor for epithelial OC: the odds ratio is from two to three-fold for patients with a diagnosis of endometriosis, compared with those who don't have it (17). The use of Metformin and sulfonylureas as well the use of NSAIDs is a protector factor, while the overweight seems to be a risk factor. There is no hard evidence that can support the consumption of tobacco and alcohol increase the risk for ovary cancer, nevertheless, they have a strong association with other types of cancer (18).

The typical clinical presentation is an adnexal mass on pelvic examination or imaging. An adnexal mass may produce symptoms like pelvic pain or pressure feeling, or it may be incidentally found on a routine pelvic examination or an imaging study performed for other clinical indications. Women with later stages may present a pelvic mass that extends beyond the adnexa. OC had historically been thought to be a silent disease. Several studies have reported non-specific symptoms in many women even at early stages, like abdominal distension, urinary symptoms like urgency or increased urinary frequency, some eating disorders, early satiety, and unspecific pelvic or abdominal pain (19). Most symptoms associated with OC are nonspecific and may also be caused by gastrointestinal, urologic, or other conditions (20). Further evaluation of symptoms that raises suspicion for OC are those of new-onset, coexisting with other symptoms, occur frequently, and are of increasing severity. Some women with OC present with postmenopausal bleeding, although women with postmenopausal bleeding should be assessed for uterine pathology before proceeding with an evaluation for OC (21). Rarely, women with OC may present with a paraneoplastic syndrome or may develop a syndrome during the course of the disease. Paraneoplastic syndromes associated with EOC include cerebellar 
Table 1 Factors involved in ovarian cancer

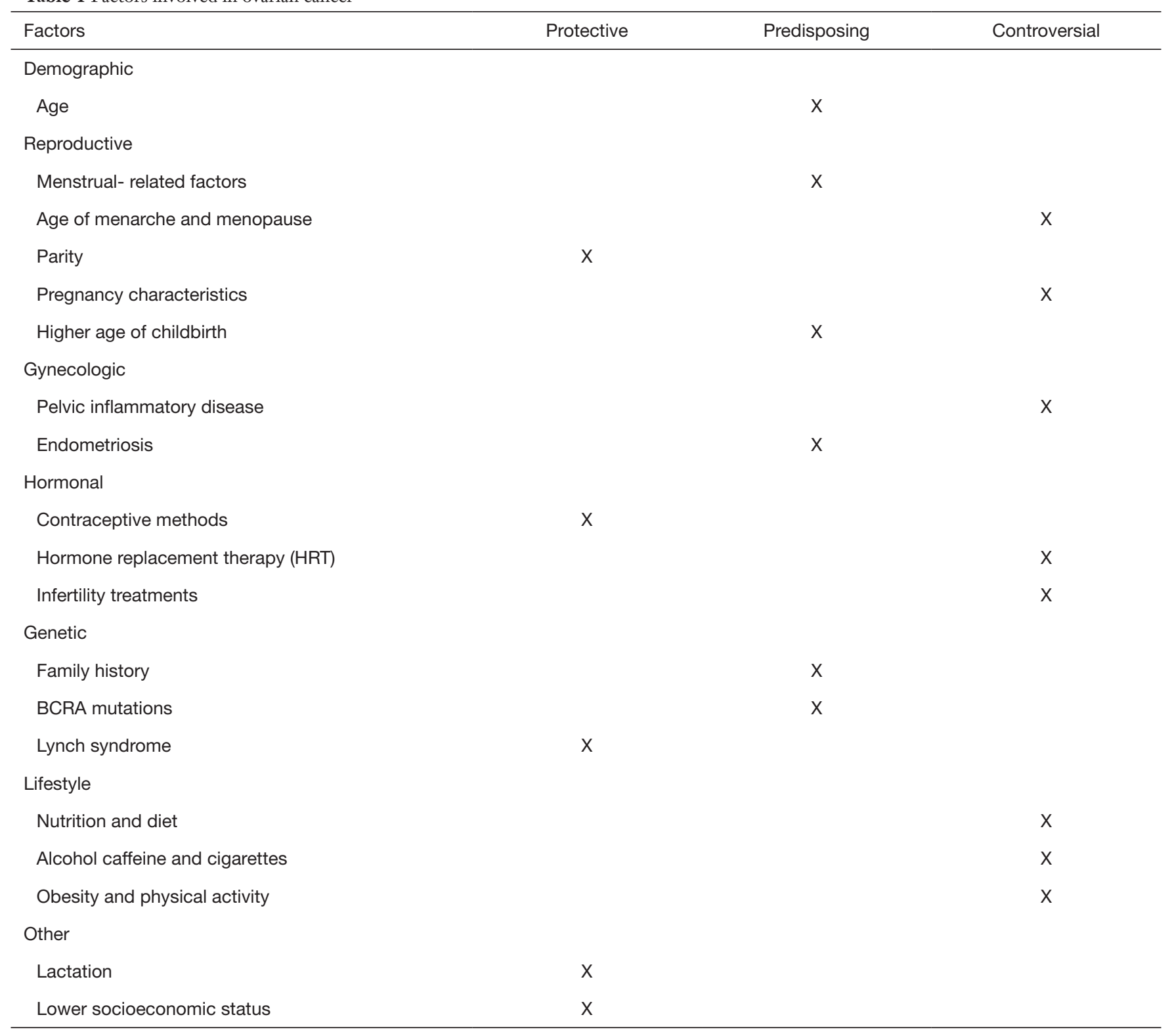

Modified from ref (1).

degeneration, polyneuritis, dermatomyositis, hemolytic anemia, disseminated intravascular coagulation, acanthosis, or nephrotic syndrome (22).

In conclusion, $\mathrm{OC}$ is one of the gynecological neoplasms with worse prognosis, but not as common as breast or cervical cancer. The incidence and mortality have variation according to the region analyzed; globally the figures are 6.6 and 3.9 per 100,000 , respectively. Various risk factors have been observed and studied, nevertheless, a deeper search should be done, most of them are non-modifiable and familial OC has to be observed. It is necessary to perform epidemiologic studies mainly in undeveloped countries in order to know the regional variation in this type of neoplasms.

\section{Acknowledgments}

Funding: None. 


\section{Footnote}

Provenance and Peer Review: This article was commissioned by the Guest Editor (Heriberto Medina-Franco) for the series "Ovarian Cancer" published in Chinese Clinical Oncology. The article was sent for external peer review organized by the Guest Editor and the editorial office.

Conflicts of Interest: All authors have completed the ICMJE uniform disclosure form (available at http://dx.doi. org/10.21037/cco-20-34). The series "Ovarian Cancer" was commissioned by the editorial office without any funding or sponsorship. The authors have no other conflicts of interest to declare.

Ethical Statement: The authors are accountable for all aspects of the work in ensuring that questions related to the accuracy or integrity of any part of the work are appropriately investigated and resolved.

Open Access Statement: This is an Open Access article distributed in accordance with the Creative Commons Attribution-NonCommercial-NoDerivs 4.0 International License (CC BY-NC-ND 4.0), which permits the noncommercial replication and distribution of the article with the strict proviso that no changes or edits are made and the original work is properly cited (including links to both the formal publication through the relevant DOI and the license). See: https://creativecommons.org/licenses/by-nc-nd/4.0/.

\section{References}

1. Momenimovahed Z, Tiznobaik A, Taheri S, et al. Ovarian cancer in the world: epidemiology and risk factors. Int J Womens Health 2019;11:287-99.

2. Holschneider CH, Berek JS. Ovarian cancer: Epidemiology, biology, and prognostic factors. Semin Surg Oncol 2000;19:3-10.

3. Braveman P, Gottlieb L. The social determinants of health: it's time to consider the causes of the causes. Public Health Rep 2014;129:19-31.

4. Patni R. Screening for Ovarian Cancer: An Update. J Midlife Health 2019;10:3-5.

5. Global Cancer Observatory [Internet]. [cited 2020 Jan 17]. Available online: https://gco.iarc.fr/

6. Prat J. FIGO Committee on Gynecologic Oncology FC on G. FIGO's staging classification for cancer of the ovary, fallopian tube, and peritoneum: abridged republication. J Gynecol Oncol 2015;26:87-9.

7. Torre LA, Trabert B, DeSantis CE, et al. Ovarian cancer statistics, 2018. CA Cancer J Clin 2018;68:284-96.

8. Reid BM, Permuth JB, Sellers TA. Epidemiology of ovarian cancer: a review. Cancer Biol Med 2017;14:9-32.

9. Boyd J. Specific Keynote: Hereditary Ovarian Cancer: What We Know. Gynecol Oncol 2003;88:S8-10.

10. Singla A. Epidemiology and Risk Factors for Ovarian Cancer. In: Preventive Oncology for the Gynecologist. Singapore: Springer Singapore, 2019:223-31.

11. Gong TT, Wu QJ, Vogtmann E, et al. Age at menarche and risk of ovarian cancer: A meta-analysis of epidemiological studies. Int J Cancer 2013;132:2894-900.

12. Modugno F, Goughnour SL, Wallack D, et al. Breastfeeding factors and risk of epithelial ovarian cancer. Gynecol Oncol 2019;153:116-22.

13. Whiteman DC, Siskind V, Purdie DM, et al. Timing of pregnancy and the risk of epithelial ovarian cancer. Cancer Epidemiol Biomarkers Prev 2003;12:42-6.

14. Beral V, Doll R, Hermon C, et al. Ovarian cancer and oral contraceptives: collaborative reanalysis of data from 45 epidemiological studies including 23257 women with ovarian cancer and 87303 controls. Lancet 2008;371:303-14.

15. Hada M, Edin ML, Hartge P, et al. Prediagnostic Serum Levels of Fatty Acid Metabolites and Risk of Ovarian Cancer in the Prostate, Lung, Colorectal, and Ovarian (PLCO) Cancer Screening Trial. Cancer Epidemiol Biomarkers Prev 2019;28:189-97.

16. Sieh W, Salvador S, McGuire V, et al. Tubal ligation and risk of ovarian cancer subtypes: a pooled analysis of casecontrol studies. Int J Epidemiol 2013;42:579-89.

17. Pearce CL, Templeman C, Rossing MA, et al. Association between endometriosis and risk of histological subtypes of ovarian cancer: a pooled analysis of case-control studies. Lancet Oncol 2012;13:385-94.

18. Beral V, Gaitskell K, Hermon C, et al. Collaborative Group on Epidemiological Studies of Ovarian Cancer. Ovarian cancer and smoking: individual participant metaanalysis including 28114 women with ovarian cancer from 51 epidemiological studies. Lancet Oncol 2012;13:946-56.

19. Goff BA, Mandel L, Muntz HG, et al. Ovarian carcinoma diagnosis. Cancer 2000;89:2068-75.

20. Olson SH, Mignone L, Nakraseive C, et al. Symptoms of ovarian cancer. Obstet Gynecol 2001;98:212-7.

21. Hippisley-Cox J, Coupland C. Identifying women with 
suspected ovarian cancer in primary care: derivation and validation of algorithm. BMJ 2011;344:d8009.

22. Shanbhogue AKP, Shanbhogue DKP, Prasad SR, et al.

Cite this article as: Gaona-Luviano P, Medina-Gaona LA, Magaña-Pérez K. Epidemiology of ovarian cancer. Chin Clin Oncol 2020;9(4):47. doi: 10.21037/cco-20-34
Clinical Syndromes Associated with Ovarian Neoplasms: A Comprehensive Review. Radiographics 2010;30:903-19. 